\title{
Article \\ Together Alone: Going Online during COVID-19 Is Changing Scientific Conferences
}

\author{
Heather J. Bray ${ }^{1,+}{ }^{\oplus}$, Jennifer Stone $\left.{ }^{2,+}{ }^{(}\right)$, Lillith Litchfield ${ }^{1}$, Kara L. Britt ${ }^{3}$, John L. Hopper ${ }^{4}$ \\ and Wendy V. Ingman ${ }^{5, *}$
}

1 School of Biological Sciences, University of Western Australia, Perth 6009, Australia; heather.bray@uwa.edu.au (H.J.B.); 21486357@student.uwa.edu.au (L.L.)

2 School of Population and Global Health, University of Western Australia, Perth 6009, Australia; Jennifer.stone@uwa.edu.au

3 Peter MacCallum Cancer Centre, Melbourne 3000, Australia; kara.britt@petermac.org

4 Centre for Epidemiology and Biostatistics, Melbourne School of Population and Global Health, The University of Melbourne, Melbourne 3051, Australia; j.hopper@unimelb.edu.au

5 Discipline of Surgery, Adelaide Medical School and Robinson Research Institute, The Queen Elizabeth Hospital, Woodville 5011, Australia

* Correspondence: wendy.ingman@adelaide.edu.au; Tel.: +61-88-222-6141

+ These authors contributed equally to this work.

check for updates

Citation: Bray, H.J.; Stone, J.; Litchfield, L.; Britt, K.L.; Hopper, J.L.; Ingman, W.V. Together Alone: Going Online during COVID-19 Is Changing Scientific Conferences. Challenges 2022, 13, 7. https:// doi.org/10.3390/challe13010007

Academic Editor: Susan L. Prescott

Received: 10 December 2021

Accepted: 15 February 2022

Published: 19 February 2022

Publisher's Note: MDPI stays neutral with regard to jurisdictional claims in published maps and institutional affiliations.

Copyright: (C) 2022 by the authors. Licensee MDPI, Basel, Switzerland. This article is an open access article distributed under the terms and conditions of the Creative Commons Attribution (CC BY) license (https:// creativecommons.org/licenses/by/ $4.0 /)$.

\begin{abstract}
The COVID-19 pandemic caused many scientific conferences to move online, posing a great challenge for scientific communication. This change offers potential advantages and disadvantages for inclusion, diversity, and scientific advancement. Here, we analyse participants' experiences of the Why Study Mammographic Density? Conference to explore some of these issues and identify key points of contention between different stakeholders. We found that while increasing participant diversity is facilitated by online conferencing, if the participants cannot interact informally with each other, there is value which is lost. In returning to in-person conferences, it will be important not to "shut the door" on those whose participation was enabled by the online format.
\end{abstract}

Keywords: COVID-19; conference; online; networking; diversity; scientific advancement

\section{Introduction}

The COVID-19 pandemic is changing the nature of scientific meetings. In 2020, many scientific organisations moved from in-person meetings to online conference platforms as their members were unable to travel internationally or gather in large groups. The sharing of research through scientific meetings is widely acknowledged to have a significant role in the research process [1], and as the vast majority of in-person meetings were cancelled, virtual conferencing technologies came to the forefront out of necessity. This has been a great challenge for the scientific community, and one which presents potential advantages and disadvantages. On one hand, online conferencing removes barriers and facilitates increased participation by groups unable to attend in-person meetings. On the other hand, a major limitation of online conferencing is the ability to re-create an authentic environment for scientists to interact and develop new ideas and collaborations.

An online conference enables participation from researchers and community members who in the past did not have the opportunity to attend in-person. Inclusion of participants from diverse cultural and experiential backgrounds at scientific conferences can foster a better scientific environment and lead to improved research outcomes [2,3]. Indeed, there is a growing call for inclusion of a wider variety of stakeholders in the research process with consumer groups taking active roles in directing the research agenda, particularly in health and medical research fields. How this sits alongside the need for scientific conferences to be places where experts can meet and freely share ideas to advance their research is unclear. There is an unexplored tension in the nature of scientific conferences, 
as conferences constitute a meeting place that facilitates both communication between scientists and communication between scientists and other non-expert stakeholders.

Clearly, the forced move from in-person to virtual meetings has been a major challenge for the scientific community, but it is one that brings with it opportunities to shape how science is communicated in the future. Here, we use the Why Study Mammographic Density? Conference as a case study of a scientific meeting that was moved to an online platform in 2020. We explore some of the issues identified, both positive and negative, when this traditionally in-person meeting moved to an online platform and identify key points of contention between different stakeholders. By sharing, we aim to encourage others to investigate stakeholders' goals and perceptions as we move forward with conferencing models that have been shaped by the unique situation caused by the COVID-19 pandemic. We also highlight potential for further exploration of the role that scientific conferences play in the communication of science as sites of dialogue between experts and non-experts.

\section{Scientific Conferences}

Although scientific conferences are considered an essential aspect of the scientific enterprise and almost all scientists are expected to attend conferences as part of their work, they have attracted little scholarly attention. In addition, there is limited examination of the communication that occurs at conferences and the role this communication plays in scientific advancement and dissemination of scientific knowledge. Scientific conferences enable the creation and sharing of scientific knowledge between experts, they provide opportunities to include non-expert stakeholders in the shaping of the research agenda, and they can also provide educational opportunities for members of the community who hold a stake in taxpayer and donor-funded research. Thus, scientific conferences can provide critical links between scientists, and between scientists and stakeholders, that improve science in many tangible ways.

From a "sociology of scientific knowledge" perspective, scientific conferences can play a part in the interpretation of research outcomes, achieving consensus, and relating the findings to broader interests [4]. In their study of the impact of "back-channel" technology on scientific conferences, Jacobs and McFarlane [4] conceptualised conferences by drawing on both sociology of scientific knowledge as well as socio-cultural theories of learning. They articulated eight aspects of scientific conferences that are critical in the creation and sharing of scientific knowledge, including the formal presentation of recent findings, (scientific) community evaluation of these findings, informal contributions from participants, and discussion and settling disagreements over these findings. Importantly, Jacobs and MacFarlane included "ensuring that, as a whole, research and/or professional practice progresses both substantively and methodologically" [4] (p. 319) as a key function of scientific conferences. Meetings enable a research field to move forward through a combination of formal presentations and informal discussions that enrich individual and group knowledge. The social networking function of scientific conferences is also a critical aspect of building collaborative relationships and trust between experts [5]. These purposes of scientific conferences are based upon pre-pandemic models that are still highly relevant today.

\section{Public Participation in Scientific Conferences}

Involving community members in research processes, such as setting research agendas, asking research questions, and communicating scientific research, is considered a significant aspect of a growing movement to make science more open and democratic, ultimately improving public trust in science [6,7]. This "participatory turn", as Jasanoff (2003) described it, sees the public as having an active role in research governance. This involves "upstream engagement" or community engagement before significant research and development has taken place and while public attitudes and representations of an issue are still being formed. As a large amount of health and medical research is funded through competitively awarded taxpayer-funded grants, there is an expectation that the 
research will benefit the public who paid for it. This is even more relevant for research funded by donations from the public. However, the positive outcomes of research for a community can take many years to achieve, and in the meantime, communities can become disenfranchised through hearing mixed information from different sources. Opening up scientific conferences to interested community members may give non-experts a chance to hear the science first-hand and view the scientific process; however, the impact on the scientific knowledge exchange functions of scientific conferences has not been explored.

Public participation in science and technology has the capacity to influence knowledge generation and increase research impact and reach. Including "end-users" or "consumers" (a term used more commonly in health science) and other non-expert stakeholders is now widely acknowledged as important for successful research translation, especially in health and medical research fields [8]. Where scientists can become focused on a research question or a failed experiment, consumers can provide necessary optimism and focus on community and patient outcomes and help to shape the research agenda [9]. Consumers can also increase dissemination of research findings in the broader community [10]. However, the interaction must occur in a meaningful way. Without direct engagement with experts, community-centred conferences and forums rarely produce actionable research or policy outcomes [11]. Therefore, non-expert community members rely on alliances with scientists who are willing to facilitate their involvement in the research process [12]. Scientific conferences offer a place where non-expert community members can be integrated with experts and make a real contribution to scientific endeavour; however, whether this occurs is yet to be determined.

\section{COVID-19 and Scientific Conferences}

The declaration of the pandemic by the World Health Organization in March 2020 came with growing COVID-19 case numbers around the world. Travel between and within countries became increasingly restricted, and in-person meetings were not possible. Many scientific meetings were cancelled outright; however, other conference organising committees chose to move their meetings to an online format rather than cancel altogether. Initially, conference organisers were largely unprepared for the move to online meetings [13], the technology was poorly implemented, and attendees and speakers lacked the necessary skills to optimally use the online format [14]. However, with this challenge also came new opportunities as the technology improved and so did the users' skills and confidence. Attendance was also facilitated for various groups who might otherwise be excluded from attending in-person meetings, such as early career researchers, researchers from developing countries, hospitalised patients, parents with small children, and people with chronic illness. The conferences were cheaper to run, $\mathrm{CO}_{2}$ emissions were reduced due to less long-distance air travel, and the general health and well-being of participants was increased with less jet lag and exposure to respiratory infections [15].

The move to online conferencing may also have provided a new opportunity to explore the role of conferences in the scientific endeavour. The traditional in-person mode of conferencing, which is considered an essential activity in scientific communities, has been disrupted, enabling a deeper analysis of its purpose. For example, many scientists use conferences as holiday time to travel, and moving online removes this respite [16], which could have longer-term consequences on scientific productivity and creativity. In addition, online technology was adopted to enable the conference to proceed; it was not chosen as the desirable platform because of benefits such as increased diversity of participants or reduced $\mathrm{CO}_{2}$ emissions. Additionally, it was not optimised for all types of interaction that occur at scientific conferences but was merely an attempt to mimic the interactions that conference organisers perceived to be the most important. The absence of these other types of interactions enables reflection on their importance, and hence analysis of the move to online conferencing can provide a better understanding of the benefits and limitations of formal and informal scientific interactions of both in-person and online conferences. 
Virtual conferences have been described as successful when they are well-attended, the scientific program is of high quality, and there is some interaction among the researchers [17]. Differences in attendance patterns have also been reported for virtual conferences, which can attract attendees from a broader range of countries in comparison to in-person conferences [13]. However, published analyses of online conferences are brief and use shallow measures such as Likert scales to gauge responding participants' opinions, often resulting in a low response rate, and they are therefore vulnerable to bias [18]. There appears to be inherent differences between online and physical mediums, and online conferences are reported to limit engagement and networking [1,16]. Virtual meetings may not focus on issues that require a high degree of trust, are controversial, or call for long-term process transformation $[19,20]$. Currently, it is unclear whether these limitations are due to poor technology implementation or inherent differences in the ability of people to interact online versus in-person $[1,14,21]$. We are yet to fully explore the impact of the change from in-person to online conferences, the value of formal versus informal interactions that occur at conferences, and what constitutes "successful" online communication.

\section{The Why Study Mammographic Density? Conference}

The Why Study Mammographic Density? Conference is a 2-day scientific meeting that has been held biennially since 2010. The conference fills a niche interest in mammographic density research, which is both a risk factor for breast cancer and masks cancer on a mammogram [22-24]. Within this specialist area, the conference is highly multidisciplinary; scientists interested in mammographic density are from the fields of biology, epidemiology, genetics, clinical medicine, and public health. Mammographic density is also a subject of intense community interest, and there are existing tensions between community members, scientists, and policy makers $[25,26]$. A number of consumer groups have formed internationally to lobby for policy changes, and therefore the conference attracts much interest from participants with a diversity of experiences and backgrounds. The sixth meeting of the Why Study Mammographic Density? Conference was scheduled to be held in Melbourne, Australia, in October 2020. However, with growing COVID-19 case numbers and increasing travel restrictions, it became clear that the conference was either to be cancelled or moved to an online platform. In May 2020, the Organising Committee (including J.S., K.L.B, J.L.H., and W.V.I.) made the decision to conduct the conference as a series of webinars.

The conference organisers reasoned that although an online form of the conference would be lacking in personal interactions, the webinar format offered a number of advantages that could be leveraged to increase overall conference attendance and maintain momentum:

- As invited speakers did not need to leave their homes to present at the conference there would be no travel costs incurred, providing greater flexibility in inviting international speakers;

- Without costs associated with invited speaker travel, as well as no cost of venue hire or catering, the webinars could be offered for free;

- The cost of participants attending the conference was further reduced as there was no need to travel or pay accommodation fees;

- The lack of financial investment to attend the conference could make the conference more appealing to community members and clinicians interested in learning about mammographic density research directly from the experts;

- By removing cost and travel barriers, the conference might attract a larger international audience.

Therefore, the COVID-19 travel restrictions had the potential to lead to a positive impact on community participation in the Why Study Mammographic Density? Conference.

With the goal of engaging with a wider international audience consisting of scientists, clinicians, and community members, the Organising Committee adjusted the content of the conference accordingly. The 2-day conference was altered to run with $2.5 \mathrm{~h}$ sessions each day over 4 days. This would enable on-screen breaks for participants to increase engagement 
and avoid "Zoom fatigue" [27]. The topics of the webinars were similar to the topics of previous meetings and included biology, measurement and screening, epidemiology and genetics, as well as an additional topic of public health policy and community. An international panel of speakers was organised, and the timing of the webinar sessions was adjusted to cater for international participants. Representatives from consumer groups were also included as invited speakers. All speakers were advised that the audience would be diverse and so they should avoid the use of jargon in their presentations where possible.

The ability to advertise the online conference to the international community was enabled by the InforMD alliance, a group of Australian breast cancer researchers fostering connections among scientists, clinicians, policy makers, and the community [28]. InforMD has a website and social media platforms that were able to reach out to the community and share information about the conference. A passionate core of community members interested in mammographic density internationally were supportive of the online format and helped to amplify the advertising on social media. The webinars were run using a Zoom video conferencing subscription through the Sir Peter MacCallum Department of Oncology, University of Melbourne. Speakers were invited to arrive $20 \mathrm{~min}$ prior to the session commencement to troubleshoot any potential problems and were sent detailed instructions on how to use Zoom and the share screen function 2 weeks prior to the meeting. The Chair opened each webinar session with a consistent and short introduction to mammographic density aimed at providing some background information for community members. Questions were encouraged from the attendees through the "Chat" and "Raise hand" functions, which have been successfully used in institute-run Zoom seminars.

The webinars commenced on the 12 October 2020 and were held over four consecutive days. Overall, 237 people expressed an interest in the conference and 152 registered for the webinars. Attendance over the course of the meeting was 111 people $(73 \%$ of those registered). This was an increase of over $60 \%$ from the previous in-person conference held in Melbourne, Australia, in 2018. The composition of the participants was 59\% academics, $10 \%$ public health/government/charity, $11 \%$ community, and $20 \%$ private industry. The involvement of diverse cultural backgrounds and community voices was a highlight of the conference. Presenters at the conference were from 11 different countries (Australia, USA, Sweden, New Zealand, South Korea, Denmark, United Kingdom, Sri Lanka, Ireland, China, Canada), and participants were from 16 countries, more than double what was previously achieved. Overall, the webinar series attracted speakers and participants from eight countries that had never before participated in the conference.

\section{Aims and Research Questions}

Conducting the Why Study Mammographic Density? Conference as a webinar series led to the increased participation, inclusion, and diversity of both presenters and audience. With the intense community interest in mammographic density research and the willingness of the conference organisers to embrace new opportunities for increasing participant diversity, this conference provided an excellent opportunity to delve into how online conferencing is shaping science communication.

The aim of this research was to use the Why Study Mammographic Density? Conference to explore how the move from in-person to online conferencing affected science communication between all stakeholders in research. The following questions were addressed:

(1) What were the Why Study Mammographic Density? Conference participants' perceptions of the online conference?

(2) Given that online conferences allow more diverse participation, what were the Why Study Mammographic Density? Conference participants' perceptions of increasing audience diversity?

This research was conducted so as to help the organisers of scientific meetings expand their ideas of success to include broader science communication principles and improve their evaluation processes. In addition, this research draws attention to the role that scientific conferences play in the broader science communication landscape. This research 
also highlights the opportunities that conferences provide for participatory engagement between stakeholders in the fundamental aspects of science that occur at conferences, given that scientific meetings are moving towards including more diverse participants.

\section{Methods}

The research was approved by the University of Western Australia Human Research Ethics Committee. One-on-one semi-structured interviews were conducted (by H.J.B.) using Zoom with three conference attendees purposefully selected from different stakeholder groups - a consumer representative, a keynote academic speaker, and a healthcare professional-to inform the development of survey questions to capture feedback regarding the participant's experience of the 2020 Why Study Mammographic Density? Conference. The healthcare professional and consumer representative were selected for interview based on their high level of engagement with the conference on social media. The academic speaker was selected as they had not attended the conference before, had not collaborated with any of the study authors, and could provide an objective, independent view. The interviews were transcribed but not subjected to thematic analysis. However, excerpts from the interviews have been included in the presentation of the results as exemplars because the interviewees gave much longer explanations than the survey respondents.

The interview script and the survey questions can be found in Supplementary Materials (Tables S1 and S2, respectively). All participants of the conference were invited to complete the resulting survey via email and survey responses, which were anonymous. The survey was hosted by Qualtrics and included basic demographic information as well as agreement, short-answer, and open-answer questions. The survey took approximately 10-15 min to complete. Open-answer questions were coded using a conventional content analysis approach [29] and analysed thematically using NVivo. Descriptive statistics were used to describe the study results using Excel.

\section{Results and Discussion}

\subsection{Survey Respondents}

Twenty-seven conference attendees responded to the survey, which was a response rate of $24 \%$. Half $(50 \%)$ of the survey respondents indicated they were researchers, with those remaining indicating that they were from a private industry, were clinicians, were community members, or had attended in a capacity other than those listed as shown in Figure 1. This distribution of respondents was similar to the conference attendees. Almost one-quarter $(24 \%)$ of the survey respondents presented at the conference, and a similar number (23\%) had attended a Why Study Mammographic Density? Conference previously, meaning that they would have attended an earlier conference in person. Of those who had attended a previous meeting, only two responded positively that the audience was more diverse than in previous years, with more members of the public, more policy makers, and more international speakers as observed differences. Three participants responded that it was not possible or not easy to have an appreciation of the audiences for the webinars. Nineteen (70\%) of the survey respondents indicated that the Why Study Mammographic Density? Conference was not the first online conference that they had attended.

\subsection{Perceptions of Online Conferences}

Within the survey, respondents were asked to indicate whether they agreed or disagreed with four statements about whether online conferences were better than in-person conferences. Overall, there was strong agreement among the survey respondents that online conferences are better for enabling attendance from a diversity of participants, with $72 \%$ either agreeing or strongly agreeing (see Figure 2). However, there was only $32 \%$ agreement (either agree or strongly agree) with the statements that online conferences are better for the community and online conferences are better for "me". There was $52 \%$ disagreement with the latter statement (either disagree or strongly disagree), indicating that the survey respondents had a preference for in-person conferences. The respondents 
agreed the least with the statement that "online conferences are better for scientific advancement" (12\% agreed or strongly agreed), although there was less disagreement on this statement ( $40 \%$ disagreed or strongly disagreed) than "online conferences are better for me". This suggests that although respondents feel more certain that they prefer in-person conferences, they also feel that in-person conferences have aspects that are important for scientific advancement that cannot be (or in this case were not) replicated within the online conference experience, which we discuss further below.

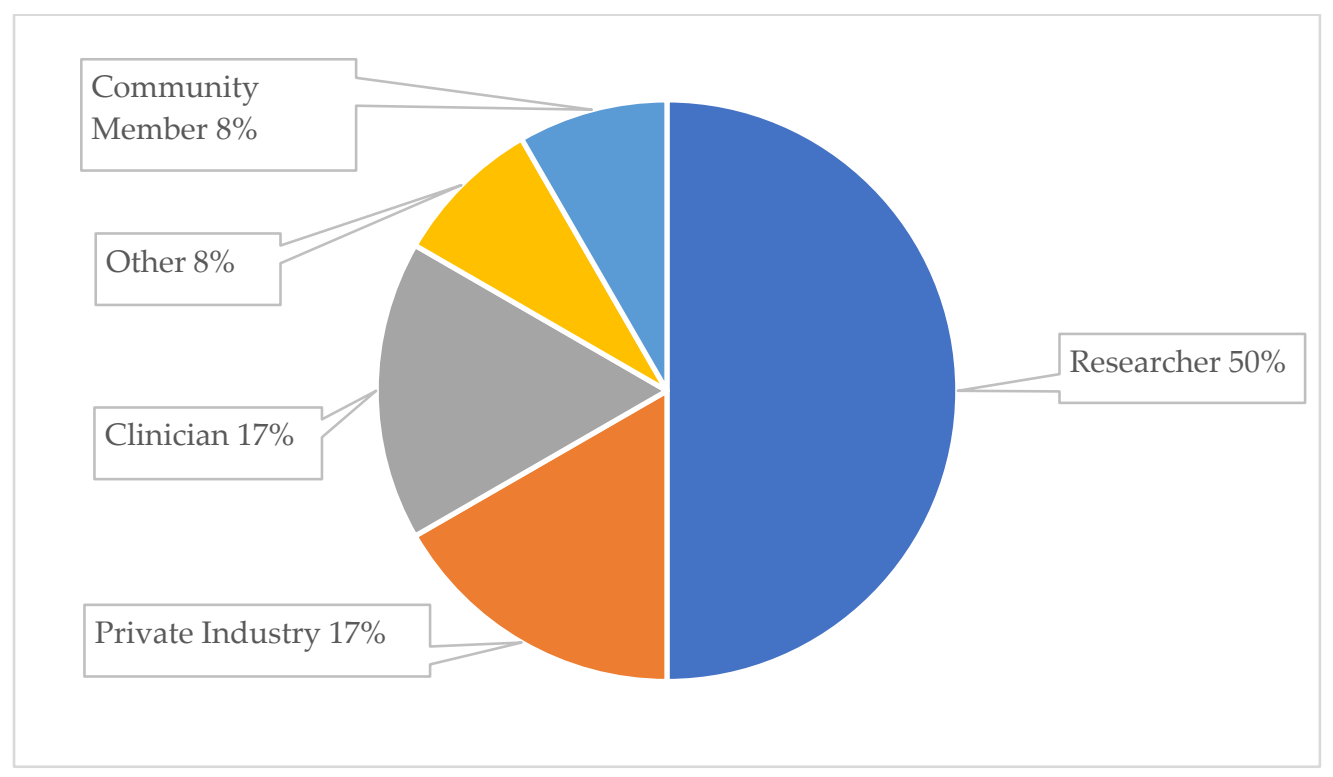

Figure 1. Capacity in which the survey respondents attended the Why Study Mammographic Density Conference.

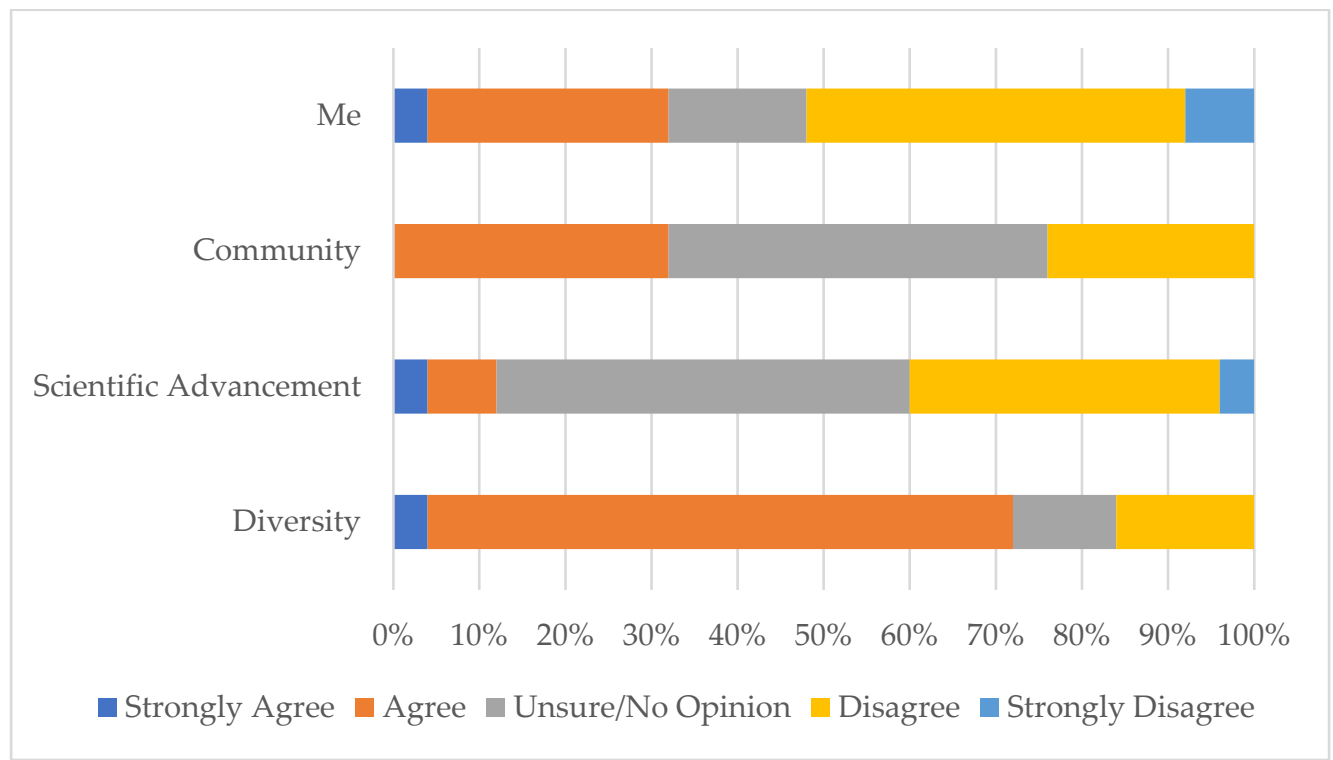

Figure 2. Participant agreement with the statement that online conferences are better for diversity, scientific advancement, the community, or themselves.

\subsection{Benefits and Downsides to Online Conferences}

Within the survey, respondents were invited to give longer answers to questions about online conferences. Content analysis from these responses revealed that lower costs was the benefit most frequently mentioned, followed by enabling a broader audience 
to attend, ease of attendance, time efficiency, and that the online environment may be more accommodating to some people (see Table 1). Costs mentioned included travel costs, scheduling issues, and ticket prices. Audience diversity was described in terms of both roles within the breast density field and attendance from people of different backgrounds and viewpoints as well as conference participant locations. Downsides most frequently mentioned included the loss of networking, loss of informal interaction, poorer discussions, and less idea exchange, time zone scheduling issues, and less community feeling (see Table 2). Survey respondents commented that they missed the corridor conversations and "one on one conversations" and "personal interactions beside the official program." Respondents also felt there was a "lack of secondary activities such as visiting nearly[sic] laboratories". One of the interviewees explained further: "[I miss] that ability to be able to network and say, $\mathrm{Hi}$, my name is such and such, this is what I do. Do you mind if I contact you in the future ... [with online] I would feel a bit cheekier, a bit more reserved about just dropping someone and email saying oh you know, I saw your presentation ... I would be a little bit more hesitant had I not physically introduced myself to them".

Table 1. Benefits to online conferences.

\begin{tabular}{|c|c|c|}
\hline Code & Count of Responses within the Code & Examples of Responses within the Code \\
\hline $\begin{array}{l}\text { Lower costs to } \\
\text { me }\end{array}$ & 16 & $\begin{array}{l}\text { "webinars are economical and time-efficient" } \\
\text { "Costs of attendance can be prohibitive for people." } \\
\text { "It saves the travel costs and time." }\end{array}$ \\
\hline $\begin{array}{c}\text { Broader } \\
\text { participation }\end{array}$ & 12 & $\begin{array}{l}\text { "it would be very difficult for everyone around the world to attend the conference in } \\
\text { person." } \\
\text { "there is no question that that provide an opportunity for broader participation and } \\
\text { involvement." } \\
\text { "the online conference clearly allowed increased participation from overseas experts } \\
\text { which was great" }\end{array}$ \\
\hline Easy to attend & 9 & $\begin{array}{l}\text { "In person conferences can be impossible to reach" } \\
\text { "Online conferences are easy to attend, do not need to travel" } \\
\text { "Ease of attendance and no cost are an advantage" }\end{array}$ \\
\hline Accommodating & 5 & $\begin{array}{c}\text { "I can multitask while attending the conference." } \\
\text { "Back to back talks at in person conferences only suit people with specific learning or } \\
\text { listening styles. It is beneficial to be able to either listen on demand or remotely drop in or } \\
\text { take focus breaks." } \\
\text { "Some people might feel more comfortable interacting in that online environment" }\end{array}$ \\
\hline Time efficient & 5 & $\begin{array}{c}\text { "no travel, shorter days than if at an in person conference" } \\
\text { "take less time out," } \\
\text { "I was able to fit it into my busy schedule" }\end{array}$ \\
\hline
\end{tabular}

Table 2. Downsides to online conferences.

\begin{tabular}{|c|c|c|}
\hline Code & Count of Responses within the Code & Examples of Responses within the Code \\
\hline $\begin{array}{c}\text { Loss of } \\
\text { networking }\end{array}$ & 15 & $\begin{array}{l}\text { "In webinars, there is limited chance to meet new people." } \\
\text { "Missed networking opportunities and one on one conversations" } \\
\text { "not very good for discussion, networking, collaboration, etc." }\end{array}$ \\
\hline $\begin{array}{l}\text { Loss of informal } \\
\text { interaction }\end{array}$ & 14 & $\begin{array}{l}\text { "the informal conversations and interactions are hugely valuable for learning } \\
\text { opportunities; discussion of research ideas and for developing collaborations" } \\
\text { "you lose the important corridor and meal break interactions and the industry support" } \\
\text { "lack of secondary activities such as visiting nearly[sic] laboratories" }\end{array}$ \\
\hline $\begin{array}{l}\text { Lack of audience } \\
\text { observation }\end{array}$ & 14 & $\begin{array}{l}\text { "We were unable to see the audience on the webinar" } \\
\text { “... you tend not to know who is in the audience, whether you are a speaker or a } \\
\text { participant." } \\
\text { “... we do not even know who else is present. That may change over time..?" }\end{array}$ \\
\hline Worse discussion & 6 & $\begin{array}{l}\text { "The disadvantage is you can also get a lot of useless chit chat or rubbish." } \\
\text { "less real human contact and discussion" } \\
\text { "Fewer opportunities to connect with peers for informal discussions." }\end{array}$ \\
\hline $\begin{array}{l}\text { Time zone } \\
\text { scheduling }\end{array}$ & 5 & $\begin{array}{l}\text { "time difference meaning some talks were in the middle of the night" } \\
\text { "I did have to miss some talks due them been very late in the evening in my time zone." } \\
\text { "Time issue, if you live on the other side of the world." }\end{array}$ \\
\hline
\end{tabular}

Most survey respondents who wrote about online modes of conferencing mentioned both positives and negatives. This, in combination with the perceptions described in 7.2 above, suggests that there is a trade-off that the respondents framed as one that is 
positive for scientific communication and ease of access but negative for scientific advancement. Respondents saw the most common reasons given for a negative opinion of online conferences-loss of networking, loss of informal interactions, and loss of discussion-as vital to scientific advancement. Many survey respondents-possibly due to the framing of the questions-framed online conferencing's problems as inherent to the medium but also hindered by a lack of skills or organisational issues in addition to inherent technological issues [14,18], leading to suggested technological-organisational solutions such as a hybrid online and in-person model. A combination of both medium and personal skills was reflected upon in a comment from one of the interviewees: "it's quite a long time to type it vs. speaking it. Additionally, ... a lot can get lost in translation ... you're so quick to type it you get really bad typos and then you know, well a wrongly spelled word could have a completely different meaning to a correctly spelled word." This interviewee also spoke of their learning curve with online conferences since the Why Study Mammographic Density? Conference was one of the first online conference they attended: " ... that was probably one of the first ones that I did do online, whereas since then, I've done two or three more. Additionally, I've actually realised that, wow, I can pause it and take a crisp screenshot ... so it's been a real learning curve for me as a delegate as well."

\subsection{Participant Diversity and Online Conferences}

As mentioned above, respondents agreed that online conferences enable a greater diversity of participants, both in terms of geographical location and roles within the breast density field, although it is the latter that is of most interest here. Respondents were asked to expound upon what they felt were the benefits (see Table 3) and challenges (see Table 4) of more diverse audiences in academic conferencing. Respondents primarily framed diverse attendance as useful, and this utility is extended to the conference, to the researchers in terms of message translation, and also to community acceptance. Respondents commented that consumers could provide new perspectives to progress science. Some respondents saw community participation as important to the translation and ultimate acceptance of research. There was also a "public understanding of science" theme within the survey responses. The other major theme regarding diverse attendance was that of obligation to the community. Similar to the Mertonian norm of science communalism, participants framed diverse attendance as fulfilling an obligation to make scientific knowledge known to the public and to allow stakeholders access to the information and processes that affect them.

As shown in Table 4, some survey respondents commented that diverse participation is not inherently better for scientific conferences, either in terms of geographically diverse participation or participation by people with diverse roles. Other survey respondents described the importance of addressing scientific needs ahead of "community" goals. The effort required to translate messages to fit non-academic audiences was seen by some to reduce the value of the conference as a space for experts to communicate in their own language. One of the interviewees, a researcher, explained this further: "and so once you're around people who understand at that [expert] level, you talk about it at a different level as well. Additionally, I think that is where you're really pushing the envelope on your own science as well ... but typically those are in the smaller meetings, those are usually the dinners at conferences, where you're sitting around the table right. Additionally, that is something that does not really happen at these online conferences." Another challenge mentioned by survey respondents was a feeling of a loss of "privacy", and therefore some topics were "skirted round." These issues were also raised within the interviews, as noted by the healthcare professional: "on the one hand you want patient advocates or the general public to have access to information at the same time you do not want to scare them with some of the cold hard facts we hear out of research." This agrees with the findings of Mader et al. (2020), who postulated that virtual conferences may not serve issues that require a high degree of trust, are controversial, or call for long-term process transformation. However, for another interviewee, a patient advocate and breast cancer survivor, being "allowed in" made them feel a part of a global movement, and given that it was their choice 
to participate, they felt that topics should not be avoided: "I do not want to be protected from it, if I am there ... if I go to a conference, I am there because I am interested, so I do not need to be shielded from it".

Table 3. Benefits of diverse conference attendees.

\begin{tabular}{|c|c|c|}
\hline Code & Count of Responses within the Code & Examples of Responses within the Code \\
\hline $\begin{array}{l}\text { Diversity is } \\
\text { useful for } \\
\text { conferences }\end{array}$ & 26 & $\begin{array}{c}\text { "other points of view are valuable" } \\
\text { "An outside higher level objective perspective can alert to issues or considerations that } \\
\text { perhaps were not entertained due to the level of detail researchers usually operate in" } \\
\text { "better and more varied content." }\end{array}$ \\
\hline $\begin{array}{l}\text { Obligation to } \\
\text { include }\end{array}$ & 9 & $\begin{array}{l}\text { "Knowledge should be available to all-especially on important topics such as } \\
\text { breast density." } \\
\text { "All stakeholders should be involved" } \\
\text { "Consumers and community members are partners in these issues." }\end{array}$ \\
\hline $\begin{array}{l}\text { Facilitates } \\
\text { message } \\
\text { translation }\end{array}$ & 5 & $\begin{array}{l}\text { "They need to understand and help us translate the critical messaging." } \\
\text { "The clearer and simpler an idea can be communicated, the better it is." } \\
\text { "it generally leads to more questions which need responses, and opens up a new channel } \\
\text { for enhanced communication. It helps break down jargon." }\end{array}$ \\
\hline $\begin{array}{l}\text { Diversity has } \\
\text { inherent benefits }\end{array}$ & 5 & $\begin{array}{l}\text { "Diversity is always enriching so any reduction of this would affect the value." } \\
\text { "to keep the diversity which is so valuable." } \\
\text { "Benefits in having broader representation." }\end{array}$ \\
\hline \multirow[b]{2}{*}{$\begin{array}{c}\text { Diversity is } \\
\text { useful to public }\end{array}$} & \multirow[b]{2}{*}{4} & $\begin{array}{l}\text { "It would give them the chance to clarify if they have any questions of scientific } \\
\text { methods/policies and raise any concerns to the scientific community" }\end{array}$ \\
\hline & & $\begin{array}{l}\text { "It is important that scientific conferences are not limited to scientists but open to diverse } \\
\text { groups of participants and have the opportunity to experience and be a part of the } \\
\text { scientific journey." }\end{array}$ \\
\hline Social licence & 3 & $\begin{array}{l}\text { "translation of findings will only happen if industry and end users (consumers) accept it." } \\
\text { "The population health and medical needs as well as the communication to these domains } \\
\text { needs to be better communicated to the dominant cultures presenting their } \\
\text { scientific results." }\end{array}$ \\
\hline
\end{tabular}

Table 4. Challenges with diverse conference attendees.

\begin{tabular}{|c|c|c|}
\hline Code & Count of Responses within the Code & Examples of Responses within the Code \\
\hline $\begin{array}{l}\text { Diversity is not } \\
\text { inherently good }\end{array}$ & 7 & $\begin{array}{l}\text { "the question assumes that the diversity of attendees is inherently always a good thing." } \\
\text { "[diversity lowering quality] depends on the fallout rate and would have to be assessed at } \\
\text { an individual event level" } \\
\text { "it would improve the diversity of attendees, but whether or not that improved } \\
\text { attendance leads to increased value or not is not obvious." }\end{array}$ \\
\hline $\begin{array}{l}\text { Message } \\
\text { translation }\end{array}$ & 6 & $\begin{array}{l}\text { "presenting the message/scientific findings/arguments in a way that a diverse } \\
\text { community understands is a challenge." } \\
\text { "Presentations need to be understood by most of the audience \& that can be challenging } \\
\text { for the presenter when explaining medical/scientific information" } \\
\text { "Some talks are just way over some peoples heads (there were some of these for me)." }\end{array}$ \\
\hline $\begin{array}{l}\text { Lowers academic } \\
\text { standard }\end{array}$ & 2 & $\begin{array}{l}\text { "I do not think the academic standard of the conference should be simplified to allow } \\
\text { participation by consumers or other participants such as GP's" } \\
\text { "Sometimes a conference that is smaller with a more focused, expert group has } \\
\text { advantages over one with mixed attendance." } \\
\text { "I do not think the academic standard of the conference should be simplified to allow } \\
\text { participation by consumers or other participants such as GP's" }\end{array}$ \\
\hline $\begin{array}{l}\text { Need to avoid } \\
\text { topics }\end{array}$ & 2 & $\begin{array}{c}\text { "[diversity in attendance] maybe skirted round more complex science v public } \\
\text { messaging stuff" } \\
\text { "Yes, wider exposure compared to privacy of a real in-person conference" }\end{array}$ \\
\hline Too many people & 2 & $\begin{array}{c}\text { "The challenge can be to ensure the intended program is fully covered while addressing } \\
\text { all relevant questions posed by participants." } \\
\text { "Challenges in terms of time to participate (whether physical or virtual) but time economy } \\
\text { (and financial) with virtual" }\end{array}$ \\
\hline $\begin{array}{l}\text { Alignment with } \\
\text { conference goals }\end{array}$ & 2 & $\begin{array}{l}\text { "I enjoyed [the conference] for the international aspect, but is that the right thing for this } \\
\text { meeting? Hmmm." } \\
\text { "for science, you want international best. For community, you want local with } \\
\text { some experts" }\end{array}$ \\
\hline
\end{tabular}

\section{Conclusions}

The movement of scientific conferences from in-person events to online activities due to the COVID-19 pandemic has brought with it an opportunity to explore how different types of communication activities are valued by conference participants. Our study, based on participants of the Why Study Mammographic Density? Conference, suggests that there 
are advantages and disadvantages associated with online conferences. While online conferences have advantages related to costs and accessibility, survey respondents, of which half were researchers, felt that the loss of the informal and spontaneous face-to-face interactions that occurs at in-person conferences contributed to online conferences being both worse for "them" as well as worse for "science", suggesting that the participants see these types of communication at scientific conferences as essential to scientific advancement. In addition, although online conferences increase participant diversity and this was seen as a benefit by survey respondents, diversity also brought with it additional challenges, namely making the information accessible to a diverse audience and reducing opportunities for researchers to speak to each other in their own language about sensitive topics.

This study highlights two tensions revealed by the disruption to scientific conferences caused by the COVID-19 pandemic and subsequent move to an online environment. Here, we mean tensions in the sense of being pulled in different directions and not in a sense of conflicts or hostilities.

The first tension relates to the important role that informal communication at scientific conferences plays in scientific advancement, in particular the "community of practice" functions such as networking and discussion [4]. Here, online conferences allow more people, experts and non-experts, industry and policy makers, to participate in the community but reduce opportunities for communication between community members. The second tension relates to the purpose of that community of practice: whether it is scientific progress, or the communication and translation of science from experts to other types of participants within the field. Although survey respondents agreed that having diverse participants was beneficial in achieving some scientific goals, such as improved problem solving and translation and acceptance of research outcomes, suggesting that the justification to include diverse audiences relates to their usefulness, some respondents also articulated obligations to share knowledge, particularly with regard to breast density. For some respondents, however, diversity reduced the opportunity to communicate in their language and about certain aspects of their research. It is likely that, had these researchers been able to meet in-person during the conference, they would be able to converse in private, even with diverse participants in attendance.

\subsection{Limitations}

This paper is based on a single case study, the Why Study Mammographic Density Conference? of 2020. We acknowledge that there is a tradition of including various stakeholders in the meeting that may not be applicable to other scientific organisations or conferences.

\subsection{Implications and Recommendations}

Although this study provides general support for hybrid conferences in the future, it is clear that conference organisers need to consider the goals of both their meeting and their community in evaluating the potential for trade-offs articulated within this paper. While increasing participant diversity aligns with current thinking about public participation in science and is facilitated by online conferencing, if the participants cannot interact informally with each other, there is value which is lost. This type of conversation is considered crucial to scientific advancement and is not replicated in other spaces. However, in returning to in-person conferences, it will also be important not to "shut the door" on those who have a vested interest in the research but can only attend online.

Supplementary Materials: The following supporting information can be downloaded at: https: / / www.mdpi.com/article/10.3390/challe13010007/s1. Table S1: Interview script; Table S2: Survey.

Author Contributions: Conceptualization, J.S., K.L.B., J.L.H., and W.V.I.; methodology, H.J.B., J.S., and W.V.I.; software, L.L.; formal analysis, H.J.B., J.S., and L.L.; writing-original draft preparation, W.V.I.; writing-review and editing, H.J.B., J.S., L.L., K.L.B., J.L.H., and W.V.I.; supervision, H.J.B., J.S., and W.V.I.; project administration, K.L.B.; funding acquisition, W.V.I. All authors have read and agreed to the published version of the manuscript. 
Funding: W.V.I. is supported by The Hospital Research Foundation Breast Cancer Fellowship.

Institutional Review Board Statement: All subjects gave their informed consent for inclusion before they participated in the study. The study was conducted in accordance with the National Statement on Ethical Conduct in Human Research, and the protocol was approved by the Ethics Committee of University of Western Australia (2021/ET000136).

Informed Consent Statement: Informed consent was obtained from all subjects involved in the study.

Data Availability Statement: Data are available on request from the corresponding author and pending ethics approval.

Acknowledgments: The authors would like to thank all participants in the 2020 Why Study Mammographic Density? Conference webinar series. Thank you to Hannah Brown for the inspiration for this research. Thank you to Peter MacCallum Department of Oncology, University of Melbourne, for hosting the Why Study Mammographic Density? Conference online.

Conflicts of Interest: The authors declare no conflict of interest.

\section{References}

1. Oester, S.; Cigliano, J.A.; Hind-Ozan, E.J.; Parsons, E.C.M. Why conferences matter-An illustration from the international marine conservation congress. Front. Mar. Sci. 2017, 4, 257. [CrossRef]

2. Entwistle, V.A.; Renfrew, M.J.; Yearley, S.; Forrester, J.; Lamont, T. Lay perspectives: Advantages for health research. BMJ 1998, 316, 463-465. [CrossRef] [PubMed]

3. Segarra, V.A.; Primus, C.; Unguez, G.A.; Edwards, A.; Etson, C.; Flores, S.C.; Fry, C.; Guillory, A.N.; Ingram, S.L.; Lawson, M.; et al. Scientific societies fostering inclusivity through speaker diversity in annual meeting programming: A call to action. Mol. Biol. Cell 2020, 31, 2495-2501. [CrossRef] [PubMed]

4. Jacobs, N.; McFarlane, A. Conferences as learning communities: Some early lessons in using 'back-channel' technologies at an academic conference-Distributed intelligence or divided attention? J. Comput. Assist. Learn. 2005, 21, 317-329. [CrossRef]

5. Wang, W.; Bai, X.; Xia, F.; Bekele, T.M.; Su, X.; Tolba, A. From triadic closure to conference closure: The role of academic conferences in promoting scientific collaborations. Scientometrics 2017, 113, 177-193. [CrossRef]

6. Irwin, A. The Politics of Talk: Coming to Terms with the 'New' Scientific Governance. Soc. Stud. Sci. 2006, 36, 299-320. [CrossRef]

7. Jasanoff, S. Technologies of humility: Citizen participation in governing science. Minerva 2003, 41, 223-244. [CrossRef]

8. Boote, J.; Telford, R.; Cooper, C. Consumer involvement in health research: A review and research agenda. Health Policy 2002, 61, 213-236. [CrossRef]

9. Ciccarella, A.; Staley, A.C.; Franco, A.T. Transforming research: Engaging patient advocates at all stages of cancer research. Ann. Transl. Med. 2018, 6, 167. [CrossRef]

10. Duncanson, E.; Dansie, K.; Gutman, T.; Tong, A.; Howell, M.; Jesudason, S.; Reidlinger, D.; Williamson, A.; Scholes-Robertson, N.; Murphy, L.; et al. 'Knowledge is power': A framework for partnering with consumers in developing and delivering a scientific meeting in nephrology. Nephrology 2020, 25, 379-383. [CrossRef]

11. Ureta, S. A failed platform: The Citizen Consensus Conference travels to Chile. Public Underst. Sci. 2016, 25, 499-511. [CrossRef] [PubMed]

12. Invernizzi, N. Public participation and democratization: Effects on the production and consumption of science and technology. Tapuya Lat. Am. Sci. Technol. Soc. 2020, 3, 227-253. [CrossRef]

13. Speirs, V. Reflections on the upsurge of virtual cancer conferences during the COVID-19 pandemic. Br. J. Cancer 2020, 123, 698-699. [CrossRef] [PubMed]

14. Wu, J.Y.; Liao, C.H.; Cheng, T.; Nian, M.W. Using Data Analytics to Investigate Attendees' Behaviors and Psychological States in a Virtual Academic Conference. Educ. Technol. Soc. 2021, 24, 75-91.

15. Counsell, C.W.W.; Elmer, F.; Lang, J.C. Shifting away from the business-as-usual approach to research conferences. Biol. Open 2020, 9, bio056705. [CrossRef]

16. Raby, C.L.; Madden, J.R. Moving academic conferences online: Aids and barriers to delegate participation. Ecol. Evol. 2021, 11, 3646-3655. [CrossRef]

17. Weiniger, C.F.; Matot, I. Craving togetherness: Planning and replanning a national society hybrid conference during the COVID-19 pandemic. Br. J. Anaesth. BJA 2021, 126, e116-e118. [CrossRef]

18. Spilker, M.; Prinsen, F.; Kalz, M. Valuing technology-enhanced academic conferences for continuing professional development. A systematic literature review. Prof. Dev. Educ. 2020, 46, 482-499. [CrossRef]

19. Mader, C.; Zimmermann, A.B.; Diethart, M.; Mula, I. Virtual conferences in higher education: Teasing out their transformative potential for sustainable development. Gaia 2020, 29, 57-59. [CrossRef]

20. Nash, C. Online Meeting Challenges in a Research Group Resulting from COVID-19 Limitations. Challenges 2021, 12, 29. [CrossRef]

21. Zierath, J.R. Building Bridges through Scientific Conferences. Cell 2016, 167, 1155-1158. [CrossRef] [PubMed] 
22. Boyd, N.F.; Guo, H.; Martin, L.J.; Sun, L.; Stone, J.; Fishell, E.; Jong, R.A.; Hislop, G.; Chiarelli, A.; Minkin, S.; et al. Mammographic Density and the Risk and Detection of Breast Cancer. N. Engl. J. Med. 2007, 356, 227-236. [CrossRef] [PubMed]

23. Huo, C.W.; Chew, G.L.; Britt, K.L.; Ingman, W.V.; Henderson, M.A.; Hopper, J.L.; Thompson, E.W. Mammographic density-a review on the current understanding of its association with breast cancer. Breast Cancer Res. Treat. 2014, 144, 479-502. [CrossRef] [PubMed]

24. McCormack, V.A.; Dos Santos Silva, I. Breast Density and Parenchymal Patterns as Markers of Breast Cancer Risk: A Meta-analysis. Cancer Epidemiol. Biomark. Prev. 2006, 15, 1159-1169. [CrossRef]

25. Cappello, N.M.; Richetelli, D.; Lee, C.I. The Impact of Breast Density Reporting Laws on Women's Awareness of DensityAssociated Risks and Conversations Regarding Supplemental Screening With Providers. J. Am. Coll. Radiol. 2019, 16, 139-146. [CrossRef]

26. Ingman, W.V.; Richards, B.; Street, J.M.; Carter, D.; Rickard, M.; Stone, J.; Dasari, P. Breast density notification: An Australian perspective. J. Clin. Med. 2020, 9, 681. [CrossRef]

27. Wiederhold, B.K. Connecting Through Technology during the Coronavirus Disease 2019 Pandemic: Avoiding "Zoom Fatigue". Cyberpsychol. Behav. Soc. Netw. 2020, 23, 437-438. [CrossRef]

28. Hugo, H.J.; Zysk, A.; Dasari, P.; Britt, K.; Hopper, J.L.; Stone, J.; Thompson, E.W.; Ingman, W.V. InforMD: A new initiative to raise public awareness about breast density. Ecancermedicalscience 2018, 12, 807. [CrossRef]

29. Hsieh, H.-F.; Shannon, S.E. Three Approaches to Qualitative Content Analysis. Qual. Health Res. 2005, 15, 1277-1288. [CrossRef] 